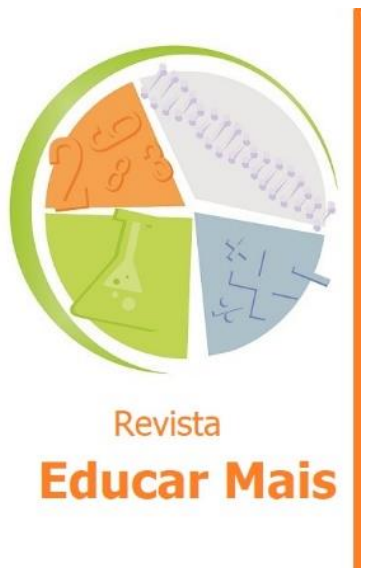

\section{A Pesquisa Baseada em Design: mapeamento de estudos relacionados ao Ensino das Ciências da Natureza}

\section{Design-based Research: mapping studies related to teaching Nature Sciences}

\section{Investigación basada en el Diseño: estudios de mapeo relacionados con la enseñanza de Ciencias de la Naturaleza}

Raquel Tusi Tamiosso ${ }^{1}$; Aline Grohe Schirmer Pigatto ${ }^{1}$

\title{
RESUMO
}

A presente pesquisa foi realizada com o objetivo de caracterizar estudos relacionados ao ensino das Ciências da Natureza que utilizaram a Pesquisa Baseada em Design enquanto pressuposto teórico-metodológico. Trata-se de uma pesquisa qualitativa, considerando sua abordagem e, bibliográfica, considerando o procedimento utilizado. As buscas foram realizadas no Portal de Periódicos CAPES/MEC e no Catálogo de Dissertações e Teses da CAPES e utilizados como descritores os termos "Pesquisa Baseada em Design" e "Design-based Research". Encontrou-se doze estudos que atenderam aos critérios estabelecidos para a busca: sete artigos, quatro dissertações e uma tese. Após a leitura e análise dos estudos selecionados constatou-se que quatro referem-se ao ensino de Física, quatro referem-se ao ensino de Biologia, um refere-se ao ensino de Química e três abordam visões gerais sobre a PBD. Nesse sentido, percebe-se que ainda são poucas as pesquisas que abordam a PBD no ensino de Ciências da Natureza. No entanto, a expectativa é que mais pesquisadores utilizem este pressuposto teórico metodológico em prol do ensino, e em especial, do ensino de Ciências da Natureza.

Palavras-chave: Revisão bibliográfica; Design-based Research; Ensino.

\begin{abstract}
This research aims to characterize studies related to the teaching of Natural Sciences that used Design-based Research as a theoretical and methodological assumption. This is a qualitative research, considering its approach, and bibliographic, considering the procedure used. The searches were performed in Portal de Periódicos CAPES/MEC and in Catálogo de Teses e Dissertações da CAPES and the terms "Pesquisa Baseada em Design " and "Design-based Research" were used as descriptors. Twelve studies were found that met the search criteria: seven articles, four dissertations and one thesis. After reading and analyzing the selected studies, it was found that four that refers to the teaching of physics, four that refers to the teaching of biology, one refers to the teaching of chemistry and three address general views on PBD. In this sense, it is clear that there is still little research that addresses PBD in the teaching of Natural Sciences. However, the expectation is that more researchers will use this theoretical methodological assumption in favor of teaching, and especially, in the teaching of Natural Sciences.
\end{abstract}

Keywords: Literature Review; Design-based Research; Teaching.

\footnotetext{
${ }^{1}$ UFN - Universidade Franciscana, Santa Maria/RS - Brasil.
} 


\section{RESUMEN}

Esta investigación se llevó a cabo con el objetivo de caracterizar los estudios relacionados con la enseñanza de las ciencias naturales que utilizaron la investigación basada en el diseño como un supuesto teórico-metodológico. Es una investigación cualitativa, considerando su enfoque y, bibliográfico, considerando el procedimiento utilizado. Las búsquedas se llevaron a cabo en el Portal de Revistas CAPES / MEC y en el Catálogo de Tesis y Tesis de CAPES y los términos "Pesquisa Baseada em Design" e "Design-based Research" se utilizaron como descriptores. Se encontraron doce estudios que cumplían los criterios establecidos para la búsqueda: siete artículos, cuatro disertaciones y una tesis. Después de leer y analizar los estudios seleccionados, se encontró que cuatro se refieren a la enseñanza de la física, cuatro se refieren a la enseñanza de la biología, uno se refiere a la enseñanza de la química y tres abordan puntos de vista generales sobre PBD. En este sentido, está claro que todavía hay pocos estudios que aborden PBD en la enseñanza de Ciencias Naturales. Sin embargo, la expectativa es que más investigadores utilizarán este supuesto teórico metodológico a favor de la enseñanza, y en particular, la enseñanza de las Ciencias Naturales.

Palabras-clave: Revisión Bibliográfica; Investigación Basada en el Diseño; Docencia.

\section{INTRODUÇÃO}

Segundo Kneubil e Pietrocola (2017), a Pesquisa Baseada em Design (PBD) refere-se a uma metodologia nova, de caráter intervencionista, que objetiva aliar aspectos teóricos e práticos da pesquisa educacional. Além disso, argumentam que na área de pesquisa em ensino de ciências, tem sido utilizada para planejar, implementar e avaliar sequência de ensino-aprendizagem (TLS) que abordam conteúdos específicos. Corroborando com esta definição, DBR-Collective (2003) também consideram a PBD uma pesquisa que combina a prática em ambientes de aprendizagem com a teoria. Argumentam que é uma metodologia importante para "[...] compreensão de como, quando e por que inovações educacionais funcionam (ou não) na prática." (DBR-Collective, 2003, p. 52) (Tradução nossa). Complementam afirmando que a PBD permite a organização de forma coerente sobre o processo de levar à sala de aula uma inovação curricular e/ou pedagógica.

Além de projetar e testar intervenções, a PBD objetiva incorporar reinvindicações teóricas sobre ensinar e aprender, refletindo um compromisso em compreender as relações entre teoria, prática e artefatos projetados (DRISOSTES, 2005). Pode-se, com a pesquisa, contribuir com aspectos teóricos da educação. Nesse sentido, Kneubil e Pietrocola (2017, p. 3)

[...] é essencial que haja uma análise do processo inteiro e não apenas do produto final, pois os resultados tirados dessa análise deverão ser incorporados na própria metodologia visando seu aprimoramento. Por isso, uma importante característica da DBR é seu funcionamento em ciclos, já que o que é aprendido de um primeiro design deve ser utilizado nos próximos designs.

A Pesquisa Baseada em Design (PBD) ou Design-based Research (DBR) foi historicamente elucidada por Brown (1992) e Collins (1992). Sua origem aconteceu após as décadas de 1955 e 1960, época marcada pela Revolução Cognitiva. No período que antecede a Revolução Cognitiva, predominavam aspectos behavioristas nas teorias de aprendizagem. A preocupação referia-se ao comportamento, e a busca pela aprendizagem realizava-se a partir de estratégias como estímulo e resposta, reforçamento e punições.

\footnotetext{
$2[\ldots]$ is an important methodology for understanding how, when, and why educational innovations work in practice.
} 
Após a Revolução Cognitiva, a preocupação migrou para aspectos referentes à mente, como memória, pensamento, solução de problemas e imaginação (LEFRANÇOIS, 2008).

O trabalho de Brown (1992) focaliza nas mudanças relacionadas às teorias de aprendizagem após a Revolução Cognitiva, enfatizando a necessidade de novas metodologias que refletissem as teorias de cunho cognitivista. Dessa forma, a PBD preocupa-se, desde sua origem, com processos mentais dos estudantes. Trata-se de uma metodologia flexível, sujeita a mudanças constantes de acordo com os acontecimentos, que exige dos professores um diagnóstico online sobre a aprendizagem dos estudantes em sala de aula. Além disso, caracteriza-se por possuir um foco de aplicação em ambientes reais de sala de aula, que, apresentam diversas variáveis (BROWN, 1992).

Esta é uma pesquisa de intervenção projetada para informar a prática. Para que isso seja verdade, devemos sempre operar sob a restrição de que uma intervenção eficaz deve ser capaz de migrar de nossa sala de aula experimental para salas de aula operadas por e para alunos e professores, apoiadas por tecnologias reais e suporte pessoal. (BROWN, 1992, p.143³). (Tradução nossa).

Collins (1992), assim como Brown (1992), chama a atenção para a questão da experimentação, dizendo que

Historicamente, algumas das melhores mentes do mundo se dedicaram à educação; por exemplo, Platão, Rousseau, Dewey, Bruner e Illich. Mas eles abordaram a educação essencialmente como teóricos, mesmo quando tentaram projetar escolas ou currículos para implementar suas ideias. $O$ que é diferente hoje é que algumas das melhores mentes do mundo estão se dirigindo à educação como experimentalistas: seu objetivo é comparar diferentes projetos para ver o que afeta o que. (COLLINS, 1992, p. $1^{4}$ ). (Tradução nossa).

Com o tempo, diversos autores foram refinando a PBD, contribuindo no processo de sistematização de suas fases e características. Wang e Hannafin (2005, p. 8) estabelecem características à PBD, quais sejam: pragmática, referindo-se a aplicação da teoria na prática, buscando o refinamento de ambas; situada, pela pesquisa ser orientada por teorias, e pela aplicação em contextos reais; interativa, uma vez que os pesquisadores envolvem-se no processo de design juntamente com os participantes (professores, gestores etc); iterativa, pela pesquisa apresentar caráter cíclico quanto a análise, design, intervenção e redesign; flexível, pela possibilidade de mudança no design inicial; integrativa, uma vez que pode integrar diversos métodos, teorias e abordagens; contextual, pela documentação do processo na íntegra (WANG; HANNAFIN, 2005).

Reeves (2000) estabeleceu quatro fases a serem seguidas para realização da PBD. A primeira consiste na análise e identificação do problema de pesquisa pelos pesquisadores e participantes (professores, gestores etc); a segunda refere-se a buscas teóricas sobre o problema e o desenvolvimento de soluções; a terceira, consiste na aplicação e teste da solução na prática; a quarta, prevê a análise e reflexão do processo para elaboração dos princípios de design, que irão contribuir com a teoria.

\footnotetext{
3 This is intervention research designed to inform practice. For this to be true, we must operate always under the constraint that an effective intervention should be able to migrate from our experimental classroom to average classrooms operated by and for average students and teachers, supported by realistic technological and personal support.

${ }^{4}$ Historically, some of the best minds in the world have addressed themselves to education; for example, Plato, Rousseau, Dewey, Bruner and Illich. But they have addressed education essentially as theorists, even where they have tried to design schools or curricula to implement their ideas. What is different today is that some of the best minds in the world are addressing themselves to education as experimentalists: their goal is to compare different designs to see what affects what.
} 
Pode-se inferir que a PBD promove mudanças em todo o contexto educacional, devido ao envolvimento dos participantes (professores, gestores), as possíveis adaptações no currículo (para o desenvolvimento da intervenção), a colaboração da instituição no que se refere ao apoio da realização da intervenção. Nesse sentido, considera-se que a PBD tem potencial para elucidar mudanças em toda a dinâmica do contexto educacional em que é desenvolvida.

\section{METODOLOGIA}

Trata-se de uma pesquisa qualitativa considerando a abordagem e, bibliográfica, considerando o seu procedimento.

Segundo Ludke e André (1986, p. 44), a pesquisa qualitativa apresenta cinco características básicas:

a) A pesquisa qualitativa tem o ambiente natural como sua fonte direta de dados e o pesquisador como seu principal instrumento; b) os dados coletados são predominantemente descritivos; c) a preocupação com o processo é muito maior do que com o produto; d) o significado que as pessoas dão às coisas e à sua vida são focos de atenção especial pelo pesquisador; e e) a análise dos dados tende a seguir um processo indutivo.

A pesquisa bibliográfica objetiva a resolução de um problema a partir de referenciais teóricos publicados, de forma a discutir e analisar os trabalhos científicos disponíveis. Isso permite conhecer sobre o que foi pesquisado, de que maneira e com qual enfoque e/ou perspectivas trataram o assunto na literatura científica (BOCCATO, 2006).

Buscamos quantificar os trabalhos existentes no ensino das Ciências da Natureza, que utilizaram a PBD, e, além disso, analisar como os autores destes trabalhos realizaram suas pesquisas. Alguns critérios foram estabelecidos para inclusão dos trabalhos, quais sejam:

- abordarem o ensino de Ciências da Natureza (de modo integrado ou os componentes curriculares separadamente ((Biologia, Química e Física);

- utilizarem os pressupostos teórico-metodológicos da Pesquisa baseada em Design;

- conterem informações gerais, revisões e/ou contribuições sobre a Pesquisa Baseada em Design no ensino de Ciências;

- preferencialmente, terem sido aplicados na escola básica;

- preferencialmente, terem sido realizados e publicados no Brasil;

Justificando os critérios de seleção, optou-se por trabalhos voltados ao ensino de Ciências da Natureza (Química, Física e Biologia), já que a presente pesquisa possui o foco no ensino destas disciplinas. Além disso, procurou-se por trabalhos guiados pelos pressupostos teórico-metodológicos da Pesquisa Baseada em Design, bem como os trabalhos que apresentassem informações gerais, revisões ou contribuições nesse âmbito com foco no ensino das Ciências da Natureza. Outro propósito da pesquisa foi identificar o que já existe sobre o assunto publicado no Brasil, para comparar e analisar trabalhos nacionais. Também, houve maior preocupação em selecionar trabalhos que fizeram aplicações na Educação Básica, mesmo que, alguns trabalhos voltados ao ensino superior tenham sido selecionados por apresentarem os demais critérios de seleção. 
As buscas foram realizadas no Portal de Periódicos CAPES/MEC e no Catálogo de Teses e Dissertações da CAPES, durante o mês de janeiro de 2019. A Figura 1 apresenta o fluxograma de seleção das publicações no Portal de periódicos CAPES/MEC.

Figura 1 - Fluxograma de seleção das publicações no Portal de periódicos CAPES/MEC.

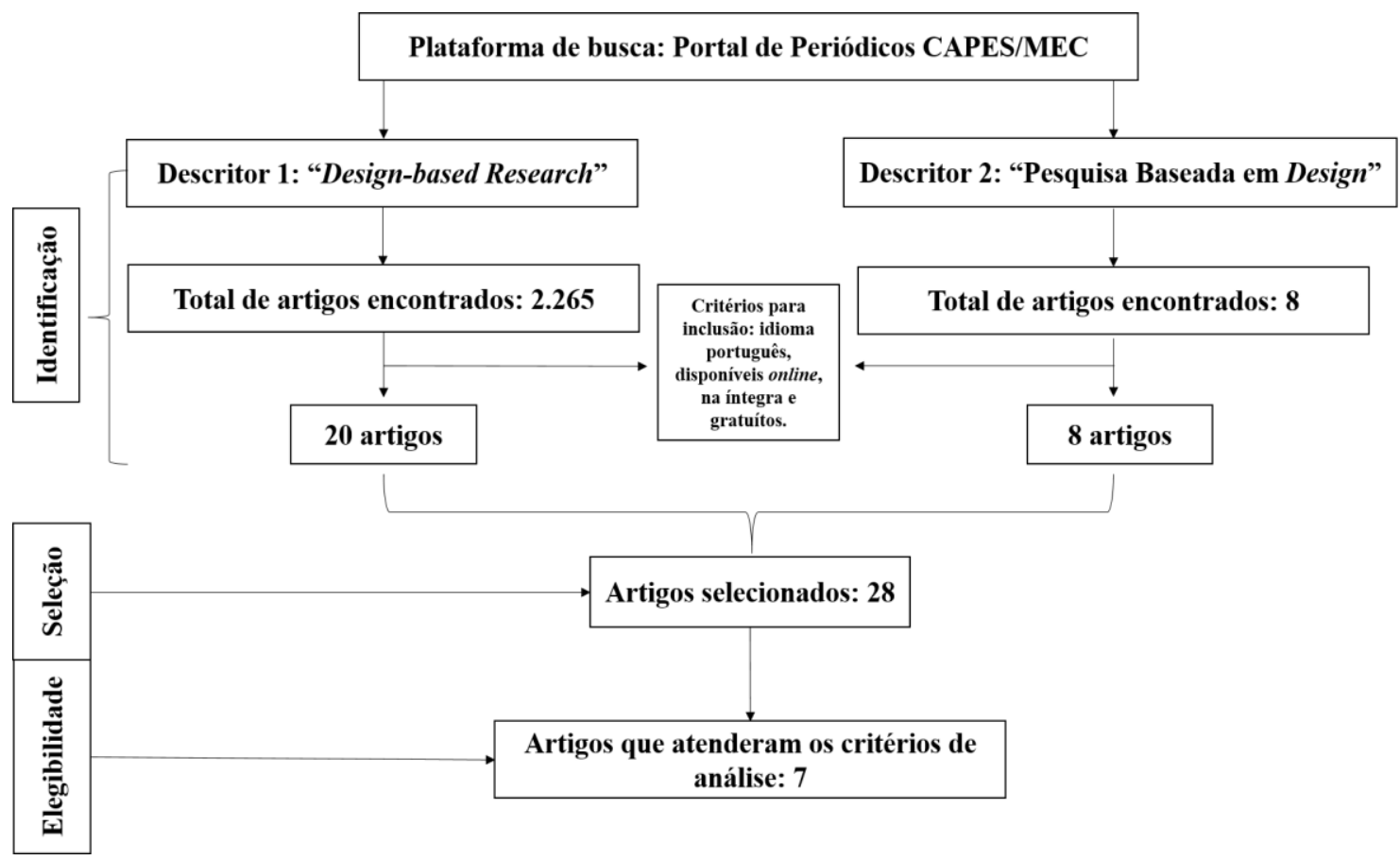

Fonte: elaborado pelas autoras.

O fluxograma de seleção das publicações no Catálogo de Teses e Dissertações da CAPES encontrase na Figura 2.

Figura 2 - Fluxograma de seleção das publicações no Catálogo de Teses e Dissertações da CAPES.

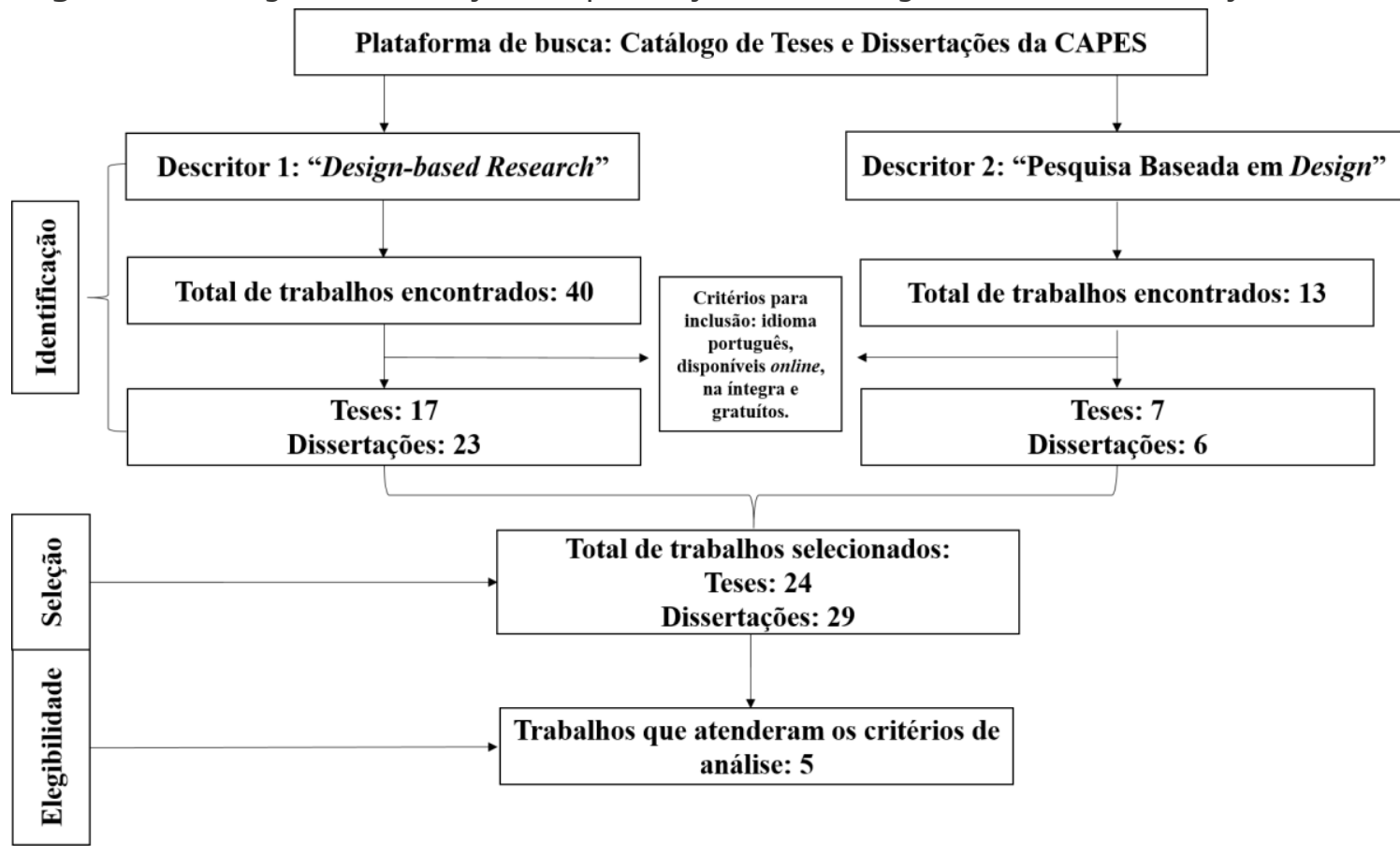

Fonte: elaborado pelas autoras. 
A busca com os descritores "Pesquisa baseada em Design" e "Design-based Research" permitiram a identificação dos trabalhos nas plataformas de busca. A seleção foi realizada contemplando trabalhos em português, disponíveis na íntegra e gratuitos. Por fim, a elegeu-se os trabalhos que atendiam os critérios de seleção pré-estabelecidos, já expostos nesse trabalho.

A primeira etapa da análise dos trabalhos selecionados possibilitou visão geral do conteúdo dos trabalhos, por meio da leitura dos resumos e fichamentos dos textos na íntegra. A etapa de exploração do material foi desenvolvida a partir da releitura dos textos, culminando na construção de sínteses sobre o que foi realizado em cada pesquisa. Posteriormente, na etapa de interpretação dos resultados, foram destacadas as principais características dos trabalhos que utilizaram a PBD.

\section{RESULTADOS E DISCUSSÕES}

O Quadro 1 apresenta os artigos recuperados na base de dados Portal de Periódicos CAPES/MEC, informando o ano de publicação, os autores, o título do estudo e o periódico no qual está publicado.

Quadro 1 - Informações referentes às publicações que fizeram parte do corpus da análise.

\begin{tabular}{|c|c|c|c|}
\hline Ano & Autor & Título & Periódico \\
\hline 2009 & $\begin{array}{l}\text { Teresa Oliveira; Ana } \\
\text { Freire; Carolina Carvalho; } \\
\text { Mário Azevedo; Sofia } \\
\text { Freire; Mónica Baptista. }\end{array}$ & $\begin{array}{l}\text { Compreendendo a aprendizagem da } \\
\text { linguagem científica na formação de } \\
\text { professores de ciências }\end{array}$ & Educar em Revista \\
\hline 2010 & $\begin{array}{l}\text { Paula Ramos; } \\
\text { Taís Rabetti Giannella; } \\
\text { Miriam Struchiner. }\end{array}$ & $\begin{array}{c}\text { A Pesquisa Baseada em Design em } \\
\text { Artigos Científicos Sobre o Uso de } \\
\text { Ambientes de Aprendizagem Mediados } \\
\text { Pelas Tecnologias da Informação e da } \\
\text { Comunicação no Ensino de } \\
\text { Ciências }\end{array}$ & $\begin{array}{l}\text { ALEXANDRIA } \\
\text { Revista de Educação } \\
\text { em Ciência e } \\
\text { Tecnologia }\end{array}$ \\
\hline 2015 & $\begin{array}{l}\text { Leylane Porto } \\
\text { Bittencourt; } \\
\text { Miriam Struchiner. }\end{array}$ & $\begin{array}{c}\text { A articulação da temática da doação de } \\
\text { sangue e o ensino de biologia no Ensino } \\
\text { Médio: uma pesquisa baseada em } \\
\text { design }\end{array}$ & $\begin{array}{c}\text { Ciência \& Educação } \\
\text { (Bauru) }\end{array}$ \\
\hline 2017 & $\begin{array}{l}\text { Carlos Alexandre dos } \\
\text { Santos Batista; } \\
\text { Maxwell Siqueira. }\end{array}$ & $\begin{array}{l}\text { A inserção da Física Moderna e } \\
\text { Contemporânea em ambientes reais de } \\
\text { sala de aula: uma sequência de ensino- } \\
\text { aprendizagem sobre a radioatividade }\end{array}$ & $\begin{array}{l}\text { Caderno Brasileiro } \\
\text { de Ensino de Física }\end{array}$ \\
\hline 2017 & $\begin{array}{l}\text { Caetano da Costa; } \\
\text { Eduardo Galembeck. }\end{array}$ & $\begin{array}{l}\text { Estudos dirigidos inovadores para a } \\
\text { aprendizagem significativa de } \\
\text { bioquímica no curso de biologia: uma } \\
\text { pesquisa baseada em design }\end{array}$ & $\begin{array}{l}\text { Revista de Ensino de } \\
\text { Bioquímica }\end{array}$ \\
\hline 2017 & $\begin{array}{l}\text { Fabiana Botelho Kneubil; } \\
\text { Maurício Pietrocola. }\end{array}$ & $\begin{array}{l}\text { A Pesquisa baseada em Design: visão } \\
\text { geral e contribuições para o Ensino de } \\
\text { Ciências }\end{array}$ & $\begin{array}{l}\text { Investigação em } \\
\text { Ensino de Ciências }\end{array}$ \\
\hline 2019 & $\begin{array}{l}\text { Carlos Alexandre Batista; } \\
\text { Maxwell Siqueira. }\end{array}$ & $\begin{array}{l}\text { Análise didática de uma atividade lúdica } \\
\text { sobre a "Instabilidade Nuclear" }\end{array}$ & $\begin{array}{c}\text { Góndola Enseñanza } \\
\text { y Aprendizaje de las } \\
\text { Ciencias }\end{array}$ \\
\hline
\end{tabular}

Fonte: elaborado pelas autoras. 
No trabalho publicado por Oliveira et al (2009), há uma descrição sobre a Pesquisa Baseada em Design como possível solução para professores no ensino de ciências, no que se refere a intenção de diminuir o fosso existente entre a teoria e as práticas docentes. O foco está na formação de professores, buscando melhorias nas formas de ensinar a partir do Design-based Research. Contextualiza a sua pesquisa devido a reforma curricular das ciências no ensino básico em Portugal, fato que elucidou mudanças na forma de ensinar. Abordam a linguagem e cultura científica como fatores importantes a serem ensinados aos estudantes. Os autores referem-se ao Design-based Research utilizando o termo em português "Investigação Baseada no Planejamento". Trazem informações relevantes sobre esta abordagem, e afirmam, entre outras coisas, que "[...] diferentes autores concordam que a Investigação Baseada no Planejamento (DBR) responde a algumas limitações que se verificam em outros tipos de investigação educacional" (OLIVEIRA et al, 2009, p.30). Para tanto, consideram a formação de professores o campo privilegiado de análise, descrevendo a DBR como uma forma de diminuir a distância existente entre a investigação educacional e as práticas docentes em sala de aula.

Ramos, Giannella e Struchiner (2010) trazem uma análise de artigos internacionais voltados ao ensino de ciências que utilizam a Pesquisa Baseada em Design para desenvolvimento de ambientes de aprendizagem mediados pelas TICs. Os autores argumentam no trabalho que buscaram por artigos brasileiros na base de dados Scielo e ABRAPEC (Associação Brasileira de Pesquisa em Ensino de Ciências) e não encontraram nenhum artigo no campo de ciências que tenha utilizado a Pesquisa Baseada em Design como metodologia da pesquisa. Portanto, o trabalho focou na análise da produção internacional. Também destacam que poucos autores buscam por caracterizar a produção acadêmica apoiada na Pesquisa Baseada em Design no ensino de ciências, justificando suas contribuições nesse âmbito. Os trabalhos recuperados foram analisados perante os problemas educativos abordados, as teorias de aprendizagem eleitas para nortear o desenvolvimento das intervenções pedagógicas, as características das intervenções e os conhecimentos construídos a partir das pesquisas. Os autores concluem dizendo que

"...a PBD é um possível caminho a ser explorado para integrar pesquisa e prática no ensino de ciências, abrindo um campo a ser investigado com maior profundidade, devendo incorporar questões específicas dos contextos educativos brasileiros". (RAMOS; GIANELLA; STRUCHINER, 2010, p. 99).

Bittencourt e Struchiner (2015) realizaram uma Pesquisa Daseada em Design na articulação da temática de doação de sangue no ensino de biologia, em uma perspectiva ciência, tecnologia e sociedade (CTS humanístico). Os autores direcionam o foco dos estudantes do terceiro ano do ensino médio para uma educação científica, tecnológica e social, ultrapassando o limiar de ensinar apenas conteúdos específicos, mas também mostrar aos alunos seu papel na sociedade.

As fases do Design-based Research delineadas por Reeves (2000) foram contempladas no trabalho e, a cada etapa, as autoras comentam como ocorreu em sua pesquisa. A definição do problema de pesquisa ocorreu em conjunto, pelos professores e pesquisadora, conforme prevê a PBD. Inicialmente, eram 6 professores do setor de biologia da escola, e, todos foram convidados a comentar como tratavam as questões sociais no ensino. Revelaram que, consideravam muito importante abordar questões sociais para que os estudantes compreendam os conteúdos de forma contextualizada. Nesta conversa, perceberam que a articulação da temática da doação de sangue nas disciplinas de Ciências/Biologia ainda não havia sido abordada por todo o grupo. Os professores concordaram sua importância e encontraram momentos nos quais poderiam abordar essa temática dentro do currículo da escola. Assim, 
a problemática partiu da articulação da temática de doação de sangue com o ensino de Biologia, de forma a envolver questões sociais e contextuais.

Um fator evidenciado foi a importância da relação de parceria entre a pesquisadora e os professores envolvidos, em especial, a professora identificada como p6, que, envolveu-se em todo o processo da PBD. Essa parceria mostrou-se fundamental para o andamento do trabalho. Como já ressaltado neste artigo, é importante que haja uma interação contínua entre o pesquisador e os professores envolvidos no ensino, para um bom andamento da Pesquisa Baseada em Design. Após a identificação da problemática, houve uma análise teórica deste problema, conforme prevê as fases da PBD. Discussões sobre as exigências do currículo de biologia emergiram, bem como formas de abordar a temática, de acordo com o currículo. Os autores utilizaram a abordagem CTS humanístico como referencial teórico, mas, também, a partir de observações realizadas nas turmas do terceiro ano do ensino médio para verificação do estilo de trabalho da professora p6 e do seu grupo de estudantes, optaram pela teoria do construtivismo social de Vygotsky, pela aprendizagem colaborativa e pela Aprendizagem Significativa de Ausubel. A construção do artefato pedagógico e o planejamento de sua aplicação nas turmas ocorreu a partir de sete reuniões entre a professora p6 e a pesquisadora.

O artefato intitulado "Doação de Sangue e o Ensino de Biologia" foi desenvolvido pela ferramenta Constructore, e, constitui-se um material educativo, "[...] que relacionou o Ensino de Biologia com Educação em Saúde, a partir da temática da doação de sangue, em seus aspectos conceituais, históricos, fisiológicos e socioculturais [...]" (BITTERNCOURT; STRUCHINER, 2015, p. 168). Durante a intervenção e aplicação do material educativo, os autores argumentam que a participação e motivação dos estudantes ficou evidente, em especial, pelos debates promovidos entre eles em aula. Quanto a avaliação do processo, os autores consideraram positiva, revelando no artigo alguns comentários dos estudantes. Segundo os autores, os estudantes conseguiram relacionar seus conhecimentos biológicos com a temática da doação de sangue, mostraram-se conscientes desta relação, e, também, perceberam as importâncias sociais da doação de sangue, conforme prevê a abordagem CTS. A professora envolvida no processo considerou o uso da tecnologia um fator importante para motivação dos alunos, apesar dela admitir ter dificuldades em lidar com as TICs. Destacou também, que, entende como alcançado o objetivo da pesquisa de integrar o ensino da Biologia com a temática da doação de sangue.

Pode-se dizer que, a utilização dos pressupostos teórico-metodológicos da Pesquisa Baseada em Design mostrou-se relevante no trabalho de Bittencourt e Struchiner (2015). Conforme é ressaltado na conclusão do trabalho, a pesquisa revelou-se uma alternativa inovadora ao ensino de biologia, apresentando atividades contextualizadas com o cotidiano dos alunos e articuladas ao conhecimento científico.

O artigo publicado por Batista e Siqueira (2017), apresenta uma sequência de ensino-aprendizagem sobre o tópico da Radioatividade. Essa sequência foi elaborada seguindo os pressupostos teóricometodológicos do Design-based Research (DBR) e da Sequência de Ensino-Aprendizagem (TLS) ${ }^{5}$. Os autores justificam a pesquisa relatando algumas inquietações quanto as inovações curriculares e metodológicas da Física Moderna e Contemporânea (FMC). Comentam que, apesar de existirem diversas produções científicas sobre o assunto, são poucos os trabalhos com referenciais teórico-metodológicos

\footnotetext{
${ }^{5}$ DBR-TLS é um referencial teórico, utilizado para informar a prática educacional. Busca desenhar um objeto de intervenção, no caso, uma sequência de ensino-aprendizagem, a fim de compreender a teoria, mas, também, informar a prática educacional. (BATISTA; SIQUEIRA, 2017). Segundo Kneubil e Pietrocola (2017), refere-se a uma sub-linha de pesquisa do DBR, "[...] que leva em cosideração a implementação de inovações curriculares inovadoras vinculadas a conteúdos específicos" (p. 4).
} 
que buscam informar como essa inovação curricular e metodológica ocorre na prática educacional. Para tanto, os autores buscam com a pesquisa, revelar aos professores e pesquisadores, como, quando e por quê a inserção da Física Moderna e Contemporânea pode ocorrer de maneira inovadora, através de intervenções práticas de sala de aula, guiadas pela DBR-TLS.

Os autores apresentam algumas características já descritas na literatura sobre a DBR-TLS, entre elas a conexão que deve existir entre as sequências de ensino-aprendizagem e a realidade da escola, bem como a necessidade do pesquisador não se colocar de forma neutra aos contextos internos e externos ao âmbito escolar. Essa característica desencadeou a escolha do tópico Radioatividade, justamente por estar conectado a realidade do local da pesquisa, na qual, os autores contextualizam explicando

[...] a relação do minério de ferro extraído de jazidas de Urânio (elemento químico naturalmente radioativo) da região de Cartité-BA, com o empreendimento federal da implantação do Complexo Intermodal Porto Sul que vai ligar as regiões OesteLeste do país por ferrovias. (BATISTA; SIQUEIRA, 2017, p. 884).

Além disso, os autores comentam que a escolha do tema também relaciona-se com a grade de conteúdos dos cursos técnicos em que a sequência foi aplicada. A sequência de ensino aprendizagem construída foi aplicada em três turmas de Física de dois Institutos Federais de Educação Ciência e Tecnologia no sul da Bahia: duas turmas eram do curso de Segurança do Trabalho e uma do curso Técnico de Informática. Os autores preocuparam-se com o ensino de Física no Ensino Médio, apesar das aplicações terem sido realizadas no ensino superior, e justificam este fato pela falta de escolas e professores com disponibilidade. Também argumentam que existe uma falta dos conteúdos de Física Moderna e Contemporânea nos currículos da escola básica.

Para o desenvolvimento da sequência sobre Radioatividade, os autores revelam que seguiram as fases de um modelo de "estrutura didática", elaborado por Lijsen e Klaassen (2004) a partir das características do DBR. Como foram realizadas duas aplicações (uma para o curso técnico de Segurança do Trabalho e outra para o curso técnico de Informática), para cada uma delas os autores relatam conhecimentos produzidos com as aplicações, reestruturando aspectos da sequência conforme prevê uma das características da Pesquisa Baseada em Design. Os autores ressaltam a iteratividade da PBD no trabalho "processo cíclico de desenho, aplicação, análise e redesenho" (BATISTA; SIQUEIRA, 2017, p.883). Encontra-se descrito no trabalho, de forma detalhada, quais foram as mudanças realizadas na sequência de ensino-aprendizagem. De acordo com Silva (2017) modificações ocorridas nas sequências de ensinoaprendizagem encontram alicerce na abordagem metodológica da Pesquisa Baseada em Design. Ou seja, a sequência de ensino aprendizagem pode ser modificada de acordo com as necessidades e exigências do contexto, para obtenção de melhores resultados. Assim, conforme relatado no artigo, os autores acreditam que a sequência de ensino-aprendizagem apresentada mostra-se como

[...] caminho essencial para transformar as demandas teórica da inovação e atualização curricular, por meio da inserção da FMC, em intervenções práticas nos ambientes reais de sala de aula, visando, em especial, uma melhoria da aprendizagem científica dos estudantes (BATISTA; SIQUEIRA, 2017, p. 889).

Neste trecho, é possível relacionarmos um dos principais propósitos da Pesquisa Baseada em Design, que visa informar a prática educacional em ambientes reais de sala de aula. Os autores também consideram que o processo cíclico da DBR-TLS mostrou-se consistente para seu trabalho, uma vez que o desenho, aplicação, análise e redesenho só foram possíveis com a aplicação prática em sala de aula, permitindo, assim, críticas, reflexões e reestruturações a partir da sequência inicial. Concluem o artigo 
explicitando suas expectativas quanto as possibilidades de outros professores e pesquisadores utilizarem a sequência de ensino-aprendizagem elaborada. Também, esperam contribuir e difundir pesquisas como essa no Brasil, a fim de melhorar a aprendizagem científica dos estudantes e, tornar aulas de Física menos tradicionais (BATISTA; SIQUEIRA, 2017).

Costa e Galembeck (2017) introduzem o trabalho com questões referentes ao ensino de bioquímica, que, conforme comentam, por vezes, são abordados aspectos descontextualizados com o conhecimento dos alunos, tornando a aprendizagem desta disciplina, mais complicada. Argumentam que, a bioquímica apresenta-se, muitas vezes, abstrata, fato que desencadeia dificuldades no entendimento dos alunos. Para o trabalho, os autores buscaram despertar a curiosidade, a motivação, uma aprendizagem mais profunda e duradoura, a partir do desenvolvimento e da aplicação de duas intervenções voltadas aos alunos do curso de Biologia. A disciplina na qual as intervenções foram realizadas foi a disciplina de Metabolismo, presente no curso de Biologia. O professor regente da disciplina é um dos autores do trabalho, enquanto o outro autor atua na pesquisa como pesquisador. Além deles, existe outro professor e quatro assistentes de ensino. Os autores explicam que a abordagem teórico-metodológica do trabalho foi o Design-based Research, e, comentam suas características e conceitos. O planejamento das intervenções, que no caso do trabalho, referem-se a estudos dirigidos, foi guiado pelo Design-based Research. Durante as intervenções, o pesquisador atuou apenas observando o comportamento dos estudantes e fazendo registros, enquanto perguntas e diálogos ficaram a cargo dos professores e assistentes. As intervenções eram contextualizadas com um problema real e com o contexto dos alunos.

Para avaliar as aplicações, os autores realizaram observações em sala de aula, análise de notas e entrevistas. Ao longo da pesquisa, as avaliações das aplicações permitiram mudanças e alterações nas intervenções, como está previsto nas fases da Pesquisa Baseada em Design. Como resultados, os autores consideraram que os estudos dirigidos e as intervenções contribuíram para o ensino e aprendizagem de bioquímica, colaborando com uma aprendizagem mais ativa e significativa.

Kneubil e Pietrocola (2017) trazem em seu artigo uma visão geral e as contribuições do Design-based Research (DBR) e da Teaching-Learning Sequence (TLS) no ensino de ciências. Os autores introduzem o trabalho trazendo questões como as necessárias inovações no ensino de ciências, sejam elas curriculares, metodológicas, relacionadas a estratégias de ensino, conteúdos, entre outros. Para tanto, comentam que a aproximação com o contexto das salas de aula permite o conhecimento das possibilidades e limitações nas propostas de ensino e aprendizagem. Relatam que pesquisas nesse âmbito, tomam por base teórico-metodológica o Design-based Research, e a definem como "pesquisa capaz de associar perspectiva teórica com aplicações educacionais práticas" (KNEUBIL; PIETROCOLA, 2017, p. 2). Acrescentam dizendo que

A DBR enquanto metodologia de pesquisa e intervenção educacional traz a vantagem de se aproximar dos problemas reais oriundos do campo escolar. A possibilidade de tratar problemas como a atualização curricular, o ensino-aprendizagem de conteúdos inovadores ou outras novas demandas no campo do social fazem dela uma poderosa ferramenta de pesquisa. (KNEUBIL; PIETROCOLA, 2017, p.12)

Os autores apresentam na sequência um tópico sobre o Design-based Research, que descreve seus conceitos e características. Ao final deste tópico, comentam que a metodologia DBR gerou uma sublinha de pesquisa, conhecida como Teaching-Learning Sequences (TLS). Esta última, leva em consideração "a implementação de inovações curriculares vinculadas a conteúdos específicos" (KNEUBIL; PIETROCOLA, 2017, p. 4). Assim, os autores descrevem um tópico sobre a TLS, no qual também 
apresentam suas características e conceitos. Argumentam que "na área de pesquisa em ensino de ciências, o Design-based Research tem sido utilizado para planejar, implementar e avaliar sequências de ensino-aprendizagem (TSL) de conteúdos específicos" (KNEUBIL; PIETROCOLA, 2017, p.1). Concluem o artigo afirmando que "as pesquisas em ensino de ciências teriam vários benefícios em adotar a metodologia DBR/TLS" (p.13).

O outro artigo publicado pelos autores Batista e Siqueira (2019), teve por objetivo evidenciar aspectos didáticos que uma atividade lúdica sobre instabilidade nuclear fornece ao ensino-aprendizagem de conceitos de Física Moderna e Contemporânea. Essa atividade é parte integrante da sequência de ensinoaprendizagem sobre Radioatividade, apresentada no artigo-de Batista e Siqueira (2017) e construída a partir dos pressupostos teórico-metodológicos da Pesquisa Baseada em Design e da Sequência de Ensino-Aprendizagem (DBR-TLS). Os autores fizeram um recorte desta atividade, utilizaram os dados provenientes de uma aplicação aos alunos do curso técnico de Informática - apresentada no trabalho de Batista e Siqueira (2017) - e, utilizaram a fundamentação da Teoria das Situações Didáticas (TSD) de Guy Brousseau, para analisar a atividade, evidenciando, em especial, seus aspectos didáticos. As análises foram realizadas a partir de gravações contendo as falas dos alunos e professores, durante a aplicação da atividade. Os autores concluem que a atividade apresenta importantes aspectos didáticos que, em contextos reais de sala de aula, são capazes de fomentar o processo de ensino-aprendizagem (BATISTA; SIQUEIRA, 2019).

Dentre os artigos analisados, dois referem-se ao ensino de física, dois ao ensino de biologia, e três estão voltados mais especificamente a apresentação de visões gerais, revisões e/ou contribuições sobre a Pesquisa Baseada em Design no ensino de ciências.

O Quadro 2 apresenta os trabalhos recuperados na base de dados Catálogo de Teses e Dissertações da CAPES, informando o ano de publicação, os autores, o título do estudo e a Instituição de Ensino na qual o trabalho foi desenvolvido.

Quadro 2 - Informações referentes às publicações que fizeram parte do corpus da análise.

\begin{tabular}{|c|c|c|c|}
\hline Ano & Autor & Título & Instituição de Ensino \\
\hline 2013 & $\begin{array}{c}\text { Leylane Porto } \\
\text { Bittencourt }\end{array}$ & $\begin{array}{c}\text { A DOAÇÃO DE SANGUE E O ENSINO DE } \\
\text { BIOLOGIA: Promovendo a sua articulação } \\
\text { através das tecnologias de informação e } \\
\text { comunicação a partir da abordagem } \\
\text { Ciência, Tecnologia e Sociedade }\end{array}$ & $\begin{array}{c}\text { Universidade Federal do Rio } \\
\text { de Janeiro }\end{array}$ \\
\hline 2014 & $\begin{array}{c}\text { Jorge Luiz } \\
\text { Nicolau Junior }\end{array}$ & $\begin{array}{c}\text { Estrutura didática baseada em Fluxo: } \\
\text { Relatividade Restrita para o Ensino Médio }\end{array}$ & Universidade de São Paulo \\
\hline 2016 & $\begin{array}{c}\text { Miler Rodrigo } \\
\text { Pereira }\end{array}$ & $\begin{array}{c}\text { História da ciência no Ensino Médio: } \\
\text { experimentos de Lazzaro Spallanzani } \\
\text { sobre reprodução animal }\end{array}$ & Universidade de São Paulo \\
\hline Sebastião & $\begin{array}{c}\text { DA WORLD WIDE WEB ÀS PARTÍCULAS } \\
\text { ELEMENTARES: sequência didática } \\
\text { baseada no método DBR-TLS com vistas a } \\
\text { alfabetização científica e técnica }\end{array}$ & Universidade Federal do Pará \\
\hline Moura & $\begin{array}{c}\text { Wanessa Klein } \\
\text { Histórias em Quadrinhos: uma alternativa } \\
\text { pedagógica para o Ensino de Química }\end{array}$ & Universidade Federal de \\
Santa Maria
\end{tabular}

Fonte: elaborado pelas autoras. 
A dissertação de Bittencourt (2013, p. 7) teve como objetivo "[...] analisar as contribuições das Tecnologias de Informação e Comunicação (TIC) no desenvolvimento de uma intervenção pedagógica que promova a articulação da temática da doação de sangue no ensino de Biologia". Um dos frutos de sua pesquisa foi o artigo Bittencourt e Struchiner (2015), já citado e comentado anteriormente. Para o desenvolvimento do trabalho, foi utilizada a Pesquisa Baseada em Design.

A autora, no primeiro momento, contou com um grupo de professores do setor de Biologia de uma escola pública do Rio de Janeiro, e, com essa parceria, foi possível identificar e analisar previamente o problema educativo em questão. Porém, apenas uma professora, que a autora nomeou de P6, participou de todas as etapas da pesquisa, que incluem a análise do problema educativo, o desenvolvimento do artefato pedagógico, a intervenção e avaliação do artefato, conforme prevê as fases da PBD, elaboradas por Reeves (2000). Os estudantes do terceiro ano do ensino médio participaram da pesquisa, e, como conteúdos programáticos, possuíam no currículo a circulação sanguínea e a tipagem sanguínea, auxiliando assim, no desenvolvimento da pesquisa (BITTENCOURT, 2013).

Durante a primeira fase da Pesquisa Baseada em Design, houve uma reunião com os todos os professores do setor de Biologia, que, fizeram uma análise preliminar do problema. Depois, houveram outras reuniões com a professora P6, para reflexões sobre o problema educativo e análise de quais momentos no currículo dos estudantes a temática do sangue estaria presente. Além disso, a pesquisadora participou de algumas aulas da professora P6 como observadora, a fim de identificar sua prática pedagógica, que, segundo a autora, foi de grande relevância para fase do desenvolvimento do artefato pedagógico (BITTENCOURT, 2013).

Na segunda fase aconteceram discussões (sete reuniões) entre a pesquisadora e a professora P6 com o objetivo de desenvolverem uma intervenção pedagógica envolvendo Ciência, Tecnologia e Sociedade, a partir da ferramenta Constructore, que promovesse a articulação do ensino de biologia e a temática de doação de sangue. Para esta construção, a autora comenta que foram utilizados livros didáticos, planos de aula da professora P6, livros e leis brasileiras da área de Hemoterapia. A autora e a professora P6, desenvolveram então, a construção da aula interativa "Doação de sangue e o Ensino de Biologia" (BITTENCOURT, 2013).

A terceira fase objetivou a implementação e avaliação da intervenção. Para isso, segundo Bittencourt (2013, p. 62), houve:

(1) acompanhamento da aula interativa, analisando o ambiente construído pelo professor e a participação dos estudantes, através do link gerência da ferramenta; (2) observação da aula interativa; (3) entrevista com os grupos de estudantes a fim de eles expressarem sobre a experiência da aula interativa e do uso da ferramenta Constructore em sala de aula; (4) entrevista com a professora P6 para avaliação da intervenção e oferecer novas ideias sobre o uso da intervenção pedagógica na disciplina.

Na quarta fase, houve a análise de todo o processo, buscando avaliar desde o problema educativo, o artefato pedagógico construído, bem como a intervenção e métodos de avaliação.

Nos resultados da dissertação, a autora analisa e discute os dados obtidos perante cada fase separadamente. Portanto, no trabalho de Bittencourt (2013), houve uma análise quanto "[...] a dinâmica do trabalho, aos fatores que influenciaram esse processo e as conclusões alcançadas a partir dos achados de cada fase." (p. 7). As análises foram feitas a partir de gravações em áudio e entrevistas que ocorreram 
ao longo da pesquisa. As conclusões da Pesquisa Baseada em Design foram satisfatórias, e, segundo a autora, atingiram os objetivos propostos.

Nicolau Junior (2014) objetivou em sua dissertação "[...] verificar se os alunos conseguem compreender os objetivos locais das atividades propostas e se a fluência das atividades já executadas permite ao aluno antever os temas das atividades seguintes" (p.12). O trabalho contou com a participação de pesquisadores e professores da Rede Pública de São Paulo. O autor conceitualiza a noção de "fluxo", e, relata que este foi o protoprincípio central no desenvolvimento de um curso sobre Relatividade Restrita, para o Ensino Médio. A Pesquisa Baseada em Design foi a metodologia utilizada, buscando contribuições ao ensino de física no ensino médio. "Um dos principais compromissos da pesquisa foi creditar importância em tornar as intenções didáticas dos professores reconhecíveis pelos alunos presentes no centro do processo didático" (NICOLAU JUNIOR, 2014, p.160). O estudo que busca inovações no ensino de física, traz consigo uma revisão relevante sobre a Pesquisa Baseada em Design na educação e no ensino de ciências especificamente.

A tese de Pereira (2014) buscou utilizar a História da Ciência como recurso pedagógico para promover discussões sobre a construção do conhecimento científico e para trabalhar um conceito específico da Biologia, a reprodução animal. O autor elaborou uma sequência-didática orientada pelos princípios da Pesquisa Baseada em Design, a fim de motivar alunos do terceiro ano do ensino médio em relação ao conteúdo proposto. Foi possível perceber que o autor se preocupou com aspectos motivacionais e emocionais dos estudantes perante o ensino de Biologia, envolvendo-os em um contexto relacionado ao conteúdo que desejava ensinar. Essa é uma característica da Pesquisa Baseada em Design, na qual o contexto deve ser levado em consideração para que o aprendizado apresente um significado para o estudante. $\mathrm{O}$ autor em suas considerações finais, ressalta que o material didático desenvolvido em seu trabalho servirá como exemplo, estando aberto e sujeito a aprimoramentos para aplicação em outros ambientes escolares ou para construção de novas sequências didáticas voltadas ao ensino de ciências.

A dissertação elaborada por Moura (2016) teve como objetivo contribuir para a melhora da prática do ensino de Física por meio da produção e aplicação de uma sequência didática, que visava a inserção da Física Moderna e contemporânea no ensino médio, bem como a observação de elementos da alfabetização científica e técnica. A pesquisa apoiou-se nos fundamentos da Pesquisa Baseada em Design (DBR) e na sequência de ensino-aprendizagem (TSL).

A dissertação construída por Klein (2018) buscou "[...] potencializar e inovar o ensino-aprendizagem de conceitos químicos por meio da produção de histórias em quadrinhos relacionadas a conteúdos abordados na disciplina de Química" (KLEIN, 2018. p. 8) de um curso superior. Para guiar todo o procedimento metodológico a autora utilizou a Pesquisa Baseada em Design, organizando todas as etapas de preparação, aplicação e análise do trabalho. A autora enumerou as seguintes etapas para realização de seu trabalho:

[...] etapa (1) momento de analisar quais conteúdos da disciplina Química Agronomia os estudantes possuem mais dificuldades; etapa (2), momento de compreender quais são os principais pontos dessas dificuldades; etapa (3), momento de traçar as estratégias de como utilizar as histórias em quadrinhos para auxiliar no ensino de química; etapa (4), momento de planejar e estruturar as histórias em quadrinhos, de modo que a complexidade do conteúdo abordado seja minimizado auxiliando na aprendizagem do estudante; etapa (5), momento da elaboração das histórias em quadrinhos no Toondoo (c) e posteriormente a compilação das HQs no Ebook, etapa (6), momento da aplicação 
do Ebook com histórias em quadrinhos e seguidamente sua avaliação (KLEIN, 2018. p.31).

Em comparação com as fases da Pesquisa Baseada em Design estabelecidas por Reeves (2006), as etapas 1 e 2 correspondem a primeira fase; as etapas 3, 4 e 5 correspondem a segunda fase; e a etapa 6 corresponde a terceira e quarta fase da Pesquisa Baseada em Design. A autora comenta que conforme a metodologia, todas as etapas podem e devem ser revisitadas sempre que necessário, constituindo os ciclos iterativos. "De acordo com essa metodologia, os registros de cada momento de ensino são utilizados para a elaboração dos próximos, como também, para a análise dos momentos de ensino já vivenciados" (KLEIN, 2018, p. 33). Completa dizendo que a partir desta constante análise, é possível fazer um redesign dos próximos momentos. Como resultados, a autora acredita que obteve uma alternativa inovadora no ensino de química com a possibilidade de utilização de linguagens alternativas, simples e ilustradas, facilitando a aprendizagem dos estudantes.

Dentre os trabalhos analisados, uma dissertação refere-se ao ensino de Química, uma dissertação e uma tese ao ensino de Biologia e duas dissertações ao ensino de Física.

Pode-se identificar uma versatilidade nos trabalhos mapeados, no que se refere às maneiras pelas quais os autores desenvolveram a PBD. Foram utilizados diferentes métodos, soluções, planejamentos e teorias, de acordo com o foco de cada trabalho. Buscou-se com as sínteses, elucidar os principais aspectos dos trabalhos mapeados, para destacar as maneiras pelas quais a PBD foi utilizada. Importante ressaltar a flexibilidade da PBD quanto a utilização de diferentes métodos e abordagens, permitindo assim, que hajam diferentes frentes de pesquisa de acordo com os anseios e objetivos dos autores.

\section{CONSIDERAÇÕES FINAIS}

Percebe-se que, em geral, ainda são poucas as pesquisas que abordam a PBD no ensino de Ciências da Natureza. Essa realidade pode ser justificada pela origem relativamente recente da PBD. Segundo Mazzardo et al (2016, p. 963) "[...] é uma abordagem de pesquisa que surgiu há pouco tempo, porém, sua implementação e as publicações são crescentes". Dentre os trabalhos mapeados, identificou-se quatro referentes ao ensino de Física, quatro referentes ao ensino de Biologia, um referente ao ensino de Química e três abordando visões gerais sobre a PBD. Nesse sentido, a expectativa é que mais pesquisadores adotem a PBD em prol do ensino, e em especial, do ensino de Ciências da Natureza.

\section{REFERÊNCIAS}

BATISTA, Carlos Alexandre dos Santos; SIQUEIRA, Maxwell. A inserção da Física Moderna e Contemporânea em ambientes reais de sala de aula: uma sequência de ensino-aprendizagem sobre radioatividade. Caderno Brasileiro de Ensino de Física, Santa Catarina, v. 34, n. 3, p. 880-902, 2017. Disponível em: https://periodicos.ufsc.br/index.php/fisica/article/view/21757941.2017v34n3p880. Acesso em: 8 jan. 2019.

BATISTA, Carlos Alexandre; SIQUEIRA, Maxwell. Análise didática de uma atividade lúdica sobre a "instabilidade nuclear". Revista Góndola Enseñanza y Aprendizaje de las Ciencias, Bogotá, v. 14, n. $1, \quad$ p. $126-142, \quad 2019 . \quad$ Disponível em: https://revistas.udistrital.edu.co/ojs/index.php/GDLA/article/view/13242. Acesso em: 28 jan. 2019. 
BITTENCOURT, Leylane; STRUCHINER, Miriam. A articulação da temática da doação de sangue e o ensino de biologia no Ensino Médio: uma pesquisa baseada em design. Revista Ciência \& Educação, Bauru, v. 21, n. 1, p. 159-176, 2015. Disponível em: http://www.scielo.br/pdf/ciedu/v21n1/1516-7313ciedu-21-01-0159.pdf. Acesso em: 8 jan. 2019.

BITTENCOURT, Leylane. A doação de sangue e o ensino de biologia: promovendo a sua articulação através das Tecnologias de Informação e Comunicação a partir da abordagem Ciência, Tecnologia e Sociedade. 2013. Dissertação (Mestrado em Educação em Ciências e Saúde) - Programa de pós-graduação em Educação em Ciências e Saúde, Universidade Federal do Rio de Janeiro, Rio de Janeiro, 2013.

BOCCATO, Vera Regina Casari. Metodologia da pesquisa bibliográfica na área odontológica e o artigo científico como forma de comunicação. Revista de Odontologia da Universidade Cidade de São Paulo, v. 18, n. 3, p. 265-274, 2006. Disponível em: < http://arquivos.cruzeirodosuleducacional.edu.br/principal/old/revista_odontologia/setembro_dezembro _2006.htm >. Acesso em: 05 dez. 2019.

BROWN, Ann Leslie. Design experiments: Theoretical and Methodological Challenges in Creating Complex Interventions in Classroom Settings. The Journal of the Learning Sciences, v. 2, n. 2, p. 141-178, 1992. Disponível em: https://www.tandfonline.com/doi/abs/10.1207/s15327809jls0202_2. Acesso em: 12 jan. 2019.

COLLINS, Allan. Towards a design science of education. In: E. Scanlon and T. O'Shea (eds). New directions in educational technology. Berlin: Springer, 1992.

COLLINS, Allan; JOSEPH, Diana; BIELACZYC, Katerine. Design research: Theoretical and methodological issues. The Journal of the Learning Sciences, v. 13, n. 1, p. 15-42, 2004. Disponível em: https://www.tandfonline.com/doi/abs/10.1207/s15327809jls1301_2 Acesso em: 12 jan. 2019.

COSTA, Caetano; GALEMBECK, Eduardo. Estudos dirigidos inovadores para a aprendizagem significativa de bioquímica no curso de biologia: uma pesquisa baseada em design. Revista de Ensino de Bioquímica, Campinas, v. 15, n. 2, p. 75-103, 2017. Disponível em: https://doaj.org/article/5c881b96463a4e82872aa028c3a2b523. Acesso: 8 jan. 2019.

DBR-COLLECTIVE. Design-Based Research: An Emerging Paradigm for Educational Inquiry. Educational Researcher, v. 32, n. 1, p. 5-8, janeiro, 2003. Disponível em: < https://journals.sagepub.com/doi/10.3102/0013189X032001005>. Acesso em: 5 jan. 2019.

DRISOSTES, Carlos Aparecido Teles. Design iterativo de um micromundo com professores de matemática do ensino fundamental. São Paulo: PUC/SP, 2005. Dissertação, Mestrado em Educação Matemática, Pontifícia Universidade Católica de São Paulo, 2005.

KLEIN, Vanessa. Histórias em quadrinhos: uma alternativa pedagógica para o ensino de química. Dissertação (Mestrado em Tecnologias Educacionais em Rede) - Programa de pós-graduação em Tecnologias Educacionais em Rede, Universidade Federal de Santa Maria, Santa Maria - RS, 2018.

KNEUBIL, Fabiano Botelho; PIETROCOLA, Maurício. A pesquisa baseada em Design: visão geral e contribuições para o ensino de ciências. Revista Investigações em Ensino de Ciências, Porto Alegre, v. 22, $\quad$ n. $2, \quad$ p. $1-16, \quad 2017 . \quad$ Disponível em: https://www.if.ufrgs.br/cref/ojs/index.php/ienci/article/view/310. Acesso em: 5 fev. 2019.

LEFRANÇOIS, Guy. Teorias da aprendizagem: o que a velha senhora disse. São Paulo: Cengage Learning, 2008. 
LUDKE, Menga; ANDRÉ, Marli. Pesquisa em Educação: abordagens qualitativas. São Paulo, Editora Pedagógica e Universitária, 1986.

MAZZARDO, Mara Denise. et al. Design-based research: desafios nos contextos escolares. In: CONGRESSO IBEROAMERICANO EM INVESTIGAÇÃO QUALITATIVA, V, 2016, Porto - Portugal. Atas. v. 1. 2016. Disponível em: https://proceedings.ciaiq.org/index.php/ciaiq2016/article/view/691. Acesso em: 02 abr. 2019.

MOURA, Sebastião. Da world wide web às partículas elementares: sequência didática baseada no método DBR-TLS com vistas à alfabetização científica e técnica. (Mestrado em Docência em Educação em Ciências e Matemática) - Programa de pós-graduação em Docência em Educação em Ciências e Matemática, Universidade Federal do Pará, Belém - PA, 2016.

NICOLAU JUNIOR, Jorge. Estrutura didática baseada em Fluxo: Relatividade Restrita para o Ensino Médio. Dissertação (Mestrado em Ensino de Ciências) - Faculdade de Educação, Universidade de São Paulo, São Paulo, 2014.

OLIVEIRA, Teresa et al. Compreendendo a aprendizagem da linguagem científica na formação de professores de ciências. Educar em Revista, Curitiba, v. 25, n. 34, p. 19-33, 2009. Disponível em: https://revistas.ufpr.br/educar/article/view/16506. Acesso em: 20 jan. 2019.

PEREIRA, Miler. História da ciência no Ensino Médio: experimentos de Lazzaro Spallanzani sobre reprodução animal. Tese (Doutorado em Ciências na área de Biologia/Genética) - Institudo de Biociências, Universidade de São Paulo, São Paulo, 2014.

RAMOS, Paula; GIANELLA, Taís Rabetti; STRUCHINER, Miriam. A pesquisa baseada em design em artigos científicos sobre o uso de ambientes de aprendizagem mediados pelas tecnologias da informação e da comunicação no ensino de ciências. Alexandria - Revista de Educação em Ciência e Tecnologia, Santa Catarina, v. 3, n. 1, p. 77-102, 2010. Disponível em: https://periodicos.ufsc.br/index.php/alexandria/article/view/38016 Acesso em: 7 jan. 2019.

REEVES, Thomas. Socially responsible educational research. Educational Technology, v. 40, n. 6, p. $19-28,2000$.

SILVA, Yasmin Alves dos Reis. Aceleradores e detectores de partículas no Ensino Médio: uma sequência de Ensino-Aprendizagem. 2017. Dissertação (mestrado em Educação em Ciências) Programa de pós-graduação em Educação em Ciências, Universidade Estadual de Santa Cruz - UESC, Ilhéus - BA, 2017.

WANG, Feng; HANNAFIN, Michael. Design-Based Research and Technology-Enhanced Learning Environments. Educational Technology Research and Development, v. 53, n. 4, 2005. Disponível em: https://link.springer.com/article/10.1007/BF02504682\#citeas. Acesso em: 15 jan. 2019. 